\title{
Strengthening social marketing research: Harnessing 'insight' through ethnography
}

\author{
Linda Brennan, \\ School of Media and Communication, RMIT, Melbourne Australia \\ Marie-Louise Fry \\ Griffith Business School, Griffith University, Brisbane Australia \\ Josephine Previte \\ UQ Business School, The University Queensland, Brisbane Australia
}

To cite this document:

Marie-Louise Fry, Linda Brennan Josephine Previte, (2015),"Strengthening social marketing research: Harnessing "insight" through ethnography", Australasian Marketing Journal, Vol. 23, pp. $286-293$.

Permanent link to this document: http://dx.doi.org/10.1016/j.ausmj.2015.10.003

\begin{abstract}
This paper aims to challenge social marketers to extend their research repertoire beyond restrictive 'individualised rationalities' driving reliance on scientifically proven evidence, population data and focus groups as insight-oriented research. Social marketing, as a discipline, is constrained by using techniques aimed at (dis)proving scientific hypotheses, thus misses the mark when it comes to creating effective social change. Gaining insight into human conduct requires research tools that examine the deep ecological context of behaviour. Ethnography has the capability to generate deep culturally based insights that captures the social world through the eyes of the consumer, yet to date remains largely underutilised in social marketing. This article explores the value of ethnography as a social marketing research method enabling in-depth and meaningful engagement with the social and cultural experiences and the performative practice that is the manifestation of human existence.
\end{abstract}

Keywords: social marketing, research insight, ethnography, behaviour change, social change, behavioural ecology 


\section{Introduction}

Societies worldwide are facing an array of social issues and health problems to which governments and not-for-profit institutions aim to seek a solution. Social marketing is a social change approach increasingly used by institutions as a mechanism to effect change within the social system (Pykett et al., 2014). As a social change methodology, social marketing has underpinned a diverse range of change programs from young women's breast feeding (Parkinson et al., 2012); reducing arson (Peattie et al., 2012); reducing drink-driving (Duong et al., 2015; Tapp et al., 2013); to child abuse (Hyman et al., 2014). These are all deep 'social' issues where behaviour change strategies must go beyond targeting the individual and incorporate a consideration of the social system in which behaviours occur. Fundamental to the success of these social marketing programs is the strategic integration, at program planning level, of deep culturally based research to harness insight as to the target audience's social reality of the phenomena under investigation. Extending beyond embedded social research is the utility of data to generate insightful and relevant social change solutions that the target audience, as member embedded within a social system, consider appropriate and doable. Yet, the extent to which social marketing programs integrate deep culturally based insight oriented research to fully comprehend the complexity of the target audiences' social circumstances and their ability to change appears under researched (for examples, see Brennan et al., 2014).

Recent commentary discussing the effectiveness of social marketing to achieve social change argues the discipline is at risk of myopia for its single focus on individual behaviour change as a measure of program success (Lefebvre, 2012; Szmigin et al., 2011). Reliance on individual level behavioural outputs reinforces individuals as sole regulators for their health and welfare (Crawshaw, 2012), which in turn constrains ability to consider 
consumers as actors operating within wider socio-cultural contexts. Critically, and in concert with Grier and Bryant (2005), we argue the over reliance on individual opinions garnered from focus groups, surveys and interviews as insight oriented research methods, the utility of population level data influencing expert driven solutions (Woolf et al., 2015) and the reliance on scientifically 'proven' evidence before acting (Capella et al., 2012) has led to inappropriately designed social change programs. Non-consideration of the wider determinants impacting behaviour change positions social marketing at risk of inadvertently stigmatising individuals and cultural groups who engage in activities that are in opposition to pervasive or institutionally sanctioned solution (Gurrieri et al., 2013), such as the stigma experienced by non-breastfeeding mothers in a culture that reifies motherhood (The VOICE Group, 2010). The continual reliance on the biomedical model and individually focussed market-managerial approaches to socio-cultural predicaments ultimately restricts capability to develop social change opportunities that not only have wide reach, but importantly target audience relevance.

As Fry $(2007,2014)$ argues, it is now time to observe behaviour change and related solutions as a human experience. Taking this opportunity, this paper contributes to strengthening the social marketing research toolkit by reflecting on the utility of ethnography as a methodology for viewing the "social world through the eyes of the consumer' (Bryman and Bell, 2007). In particular, we aim to inspire and motivate social marketers to infuse self-reflexivity in their assumptions and methods when planning social change programs, and importantly shift away from the restrictive paradigm of 'individualised rationalities' towards more thoughtful consideration of viewing social issues within a behavioural ecology lens.

The following discussion elaborates on the term 'insight' as a critical phase of social marketing planning, and then discusses issues limiting social marketers' capability to 
harness 'deep' insight of the behavioural ecology of the phenomena under consideration. We then discuss the value of ethnography to social marketing, and illustrate this value with an overview of how specific ethnographic techniques provide opportunities for social marketing practice. It is beyond the scope of this paper to discuss each technique in-depth, but rather the objective of the paper to extend social marketers' research toolkit to explore more about the 'why' of the consumer behaviour to uncover the dynamics behind the micro-level consumer's behaviours as it occurs within their behavioural ecologies. The tools are presented with a view to adding to the social marketer's repertoire of alternative approaches to deepen their insight into the social systems in which behaviours are embedded.

\section{Delineating social marketing 'insight'}

Prior to discussing the utility of ethnography to social marketing, we engage a discussion as to the meaning of 'insight' in relation to social marketing. Social marketing is widely accepted as a social change mechanism which aims to increase the acceptability of a social idea or practice across society to achieve a social good (Andreasen, 2002). Effective social marketing relies on the development of relevant and viable interventions that resonate with the target audience. Central to this process is the harnessing of deep, meaningful insight of consumers' behaviours, roles, networks of interactions, co-created outcomes and practices in order to develop understanding of the social issue under investigation. Stone et al. (2004) view insight as a process of engaging research that enables capability to get close to the target audience in order to perceive clearly or deeply. The UK based National Social Marketing Centre view insight as that 'pivotal piece of understanding into the target audience that is achieved by moving beyond simply looking 
at demographic or epidemiological issues to focus on what 'moves and motivates' people' (NMSC, 2015). Echoing these positions French et al. (2010, p. 99) articulate 'insight' as that 'discovery of deeper or hidden meaning' into consumer's experiences in relation to the social issue. They further contend effective behavioural change is underpinned by harnessing consumer insight, and as such 'insight' is of paramount importance in designing social marketing strategies that 'work'.

These views of insight suggest the term is not unidimensional, but rather is eclectic in nature. As such, it borrows from the variety of traditions that have formed the foundation of marketing and therefore social marketing (Brennan et al., 2014; Dann et al., 2007). Nonetheless, there is certainly a commonality across the varied interpretations of insight. Fundamentally, insight refers to viewing the phenomena of interest through the eyes of the consumer in the aim to capture the deep truths as to the experiences, behaviours, beliefs and the ways of life of consumers in relation to the social issue of interest. Furthermore, insight is that 'aha' or 'Eureka' moment that enables the examiner to 'see' what can be done with the issue under scrutiny (Smith and Yang, 2004). This thinking extends beyond simply considering individual level impacts; requiring consideration of individuals as social actors within a market-space, and of behaviour change as operating as a social interaction between actors within a dynamic and interactive market system.

Additionally, Stone (2004) distinguishes between insight, as an aspect of the data capturing process, as opposed to insights that serve as a functional output of the process of capturing insight. In this way insights refer to those 'flashes of inspiration or penetrating discoveries that can lead to specific opportunities' for leveraging the value exchange entity. As such, the value of harnessing consumer insight is to help structure social change program thinking and decision making, but more importantly to identify the value exchange entity with which consumers will identify. The value exchange entity is the 
'thing' that brings the consumer and the social marketer to the market space where interaction and engagement may result in value being created and exchanged (and possibly re-created and re-exchanged until the parties are content with the outcome). The entity may be co-created (Aggarwal and Basu, 2014), or it may be created by the social marketer and offered in exchange for some desired outcome (for the social marketer) and benefit for the consumer (Layton, 2011). As Peattie and Peattie (2003) note, the effectiveness of behaviour change lies in development of new sustainable practices that have relevance and meaning, and reproduction capability. Within this frame, 'insight oriented' research acts as a strategic tool within social marketing to unveil the hidden truths of consumer experiences and lived reality associated with social issues.

\section{Limitations to harnessing 'insight' in social marketing}

Influencing and facilitating individual and social change is notoriously difficult (Guidry et al., 2014; Geller, 2002). Yet, the key to achieving improved health and social outcomes hinges on designing social marketing programs grounded in quality evidence and an indepth understanding of the target audience as social actors within a market-space of engaged interactions that both define and design the shared outcomes. Despite the breadth of social marketing as a social change tool, there remain remarkably few examples of truly successful sustainable social change programs (Langford and Panter-Brick, 2013). Many interventions are poorly designed, demonstrate a lack of theoretical underpinning and are based on theoretical foundations that may not be commensurable given the context (i.e. they may be ecologically invalid (Bronfenbrenner, 1979, Brennan et al., 2014)). For example, there remains an overreliance on social advertising, particularly threat appeals as an educative motivator to stem risky behaviour, alongside continued attention to 
addressing rational, cognitive drivers of behaviour (Kessels et al., 2014; Kim et al., 2014). Although this theme of research is recognised as a valued and crucial step in the early stages of program development, few extant evaluations provide details on integration of indepth socio-cultural oriented research, although there are some (e.g. Panter et al., 2013; Polonsky et al., 2010). Some of this is potentially due to the application of biomedical models of research and the widespread reliance on experimental designs that by default limit the research context to laboratory conditions (e.g. Dixon et al., 2014; Sweeney and Moyer, 2015).

However, a social change agenda must look beyond individual behaviour change under constrained conditions to the bigger picture that is the meso-level social system and the society in which the individual is embedded. The use of social marketing is fraught with concerns of paternalism and limits to freedom (Battle-Fisher, 2015; Chang et al., 2013; Cherrier and Gurrieri, 2014). Indeed, recent social marketing scholarship directs much attention to the neoliberal co-optation of social marketing as a structural ideology constraining capability of social marketing to effect social change (Crawshaw, 2012; Tadajewski et al., 2014). Neoliberal ideology frames and constructs social change as an individualised consumption entity, where individuals are responsible for their choices, decisions and management of risks (Fitchett, et al., 2014). Within this lens, the requirement for social change is premised on a dichotomous moral interpretation of the phenomenon under consideration (Askegaard and Linnet, 2011; Askegaard et al., 2014). For example, alcohol is largely framed within a moral lens and discourse of 'responsible/non-binge', or as 'excessive/binge' drinking, with outcomes constrained within categories of 'desirable versus undesirable' behaviour. Food consumption moralities align 'good' food items as more healthy than those construed as 'bad', with consumption outcomes affecting 
moralities regarding acceptability of body size, social (non)acceptance and media (re)interpretations constructing the healthy diet (Askegaard et al., 2014).

Developing understanding of the nexus around consumers' responsiveness to a social issue, the interactions between individuals as related to the social issue, and structures in society impacting behaviour is critical for effective social marketing. Insight not only yields capability to develop effective social change programs, but also leverages capability for social change designers to create mutually satisfying exchanges to which consumers will be responsive. Echoing Peattie and Peattie (2003, p. 377), social marketing faces the 'challenge of attempting to change behaviour without properly understanding or responding to the social context that shapes that behaviour'. Attention must be directed towards ensuring research strategies use insights relating to individuals as operating within a dynamic, evolving market space, where human engagement, intersubjectivity and interactions lead to their co-created performances of daily life. Furthermore, such insights must be cognisant of the entire ecology, including the political, social, cultural, economic and behavioural landscape. An understanding of the behavioural ecology will transcend any individual research project and will of necessity be built up over time and in a naturalistic environment. Therefore, knowledge, as a strategic asset, will be multidimensional and multi-disciplinary and shared all relevant participants in the knowledge system. New methods are required for a communitarian approach to research in a globalised and post-colonial world (Denzin, 2011). In particular, research that supports public policy decision-making, such as social marketing, has a moral responsibility to authentically represent the affected populations and audiences, including the entire panoply of the lived experiences of citizens.

However, the extent to which consumer research is considered a strategic asset in the planning stages of developing social change programs is a moot point. The issue centres on 
the extent to which research is engaged to understand the lived reality of consumers and the social patterning of the social issue. At a surface level, focus groups are useful for exploring individual's feelings, motivations and concerns that are often at the centre of social marketing research. Focus group methodology can help generate information and ideas on social behaviours and practices and, in social marketing, are especially useful for understanding group responses to normative injunctions (Duong et al., 2015). However, as Duong et al. found descriptive norms were more indicative of behaviour in the road safety context. This additional insight came about as a result of careful observations of road safety behaviours and traffic flows in Vietnam; realising that self-reported intended comportment in a focus group becomes impossible to achieve when faced with the traffic conditions in Ho Chi Minh City. In another study Gallegos and colleagues (2011) conducted focus groups to explore if technology solutions, such as health apps and textbased support messages, could have a role in ameliorating health risks associated with short duration breastfeeding. Their focus group data supports the argument that technology can act as a social support tool, as it provides a sense of controlled connectivity and personalisation of health messages. Their qualitative insights were more recently supported with findings from experimental research, which surveyed women following their use of a text-based social marketing intervention (Gallegos et al., 2014). Reminder text messaging improves some women's breastfeeding behaviour (e.g., extending the duration of their breastfeeding), yet the question remains: how these discrete individual studies about women who breastfeed can be applied to address the wider challenges associated with sustaining a desired health behaviour. To better understand sustained behaviour change, social marketers need a diverse set of research methods and evidence that informs social change programs beyond the individual's perspective, at a discrete period of time. Whilst focus groups allow observation of interactions between group participants to be observed 
and an opportunity to capture rich accounts of participants' experiences, focus group data nonetheless is largely representative of individual-level analysis, and has limited capability to harness insight as to the how the individual operates within wider socio-cultural context and within the behavioural ecology (Agafonoff, 2006).

\section{Ethnography and social marketing}

As stated in the call for papers for this special issue, ethnography has a venerable tradition dating back over 150 years. As such, ethnography in marketing and social research is not new. However both social and consumer marketers have become increasingly frustrated with the inability of traditional research methods to predict behaviour (Sniehotta et al., 2014). The biomedical model has failed to control sufficient variables to be certain that their experiments will provide the evidence required to successfully design interventions (see for example, Humphreys and Manuel, 2014; Moss et al., 2015). These projects found that their interventions produced counter-intuitive, unexpected and socially undesirable results. Ethnography holds a distinct advantage in this regard. By observing actual behaviour and then understanding the reasons underlying this behaviour, marketing and social researchers have a tool to 'close the gap' and to design strategies inclusive of a behavioural ecology. Whilst it is consumer marketers that have driven ethnography to the forefront of qualitative research, it is in government and social marketing where the gap between actual versus stated behaviour is arguably the largest. This is possibly because governments aim to 'prevent' undesirable behaviours and 'intervene' in naturalistic settings in order to bring about behaviour change to align with government goals, not individual ones, thus working against natural proclivities instead of 
with them. However, when government policy is the driver of many behaviour change strategies (Hackley et al., 2015; Snitow and Brennan, 2011; Warin et al., 2015) and a significant funder of social advertising in Australia with more than $\$ 100$ million spent each year (Allday, 2015), the necessity of getting it right becomes critical.

As outlined in Figure 1, ethnography is a research tool embedded in the epistemological traditions of anthropological research, whereby human culture, traditions, rituals, signs, symbols and behaviour are observed, examined and reflected upon to create an interpreted understanding of the reality that has been observed (Agar, 2001; Allard \& Anderson, 2005). Thus, the social world of the consumer is recreated (externalised and described by the researcher) for the purpose of designing social marketing strategies to benefit society. Important to this conceptualisation of ethnography as a tool is the relative ontology that applies to research in this tradition. The ethnographer adopts the position that the phenomena under examination will vary according to social, political, cultural, situational, personal, historical and environmental conditions.

Figure 1: Social Marketing Ethnographic Process 


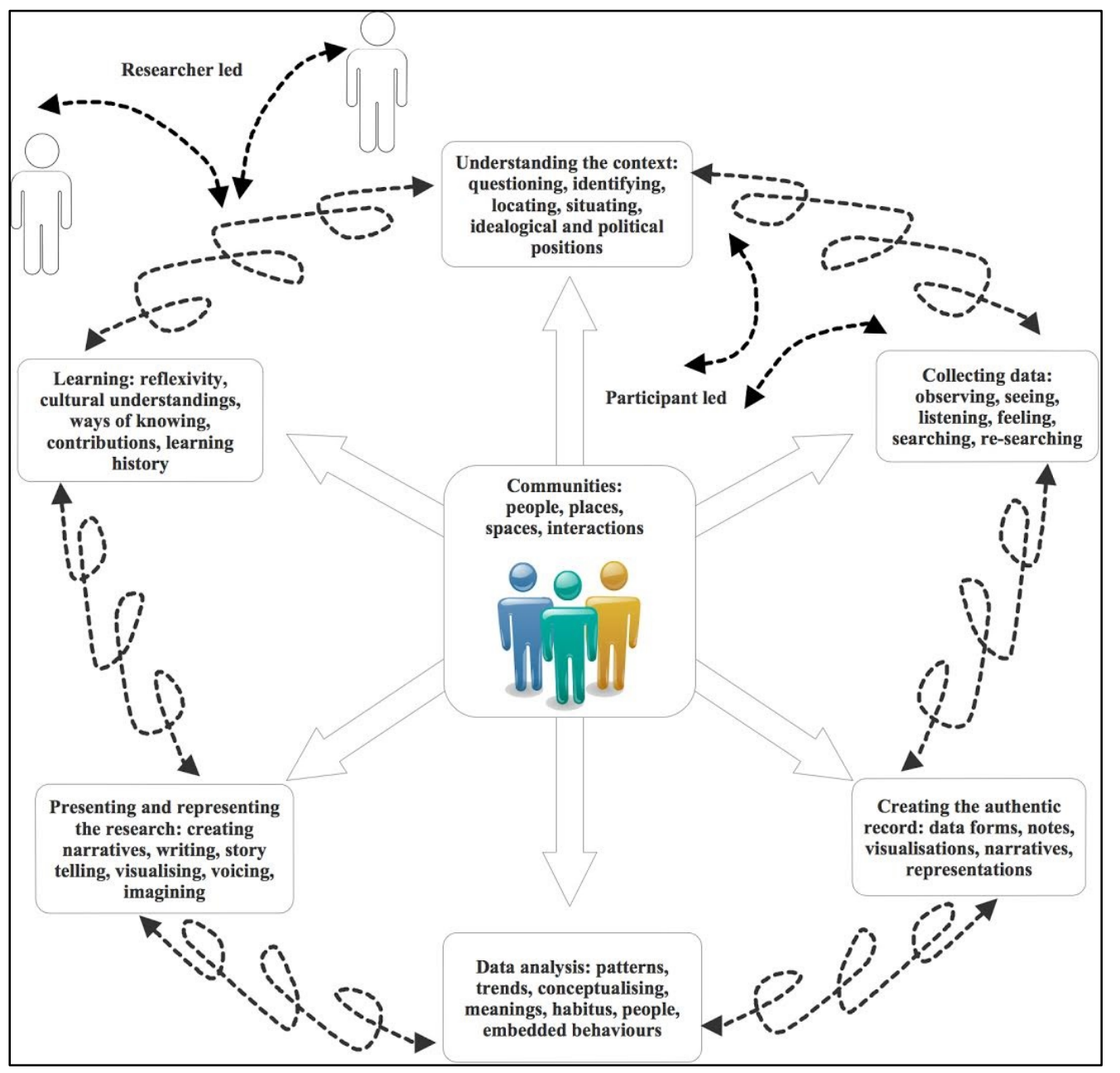

Hence, the 'truth' will vary, even when recreated rigorously and objectively (Bronfenbrenner, 1979). For social marketers, this may mean creating and recreating strategies to suit different contexts. It also means that what works in one context may not work in another. We argue that researchers interested in understanding the behavioural ecology in which behaviours occur should embrace ethnographic research, as it will enable a deeper engagement with the consumer's context. This, in turn, will provide greater knowledge and inspire further insight into the barriers and facilitators of social change within the human ecology (Bronfenbrenner, 2005).

Ethnography is not a simple procedure or single set of tools and techniques that provide research outcomes. It incorporates a variety of approaches embedded within the qualitative traditions. Ethnographic research is a boundary-less process in which the researcher and 
the researched are integrally engaged, changing and being changed over time and as a result of the engagement. Data in the ethnographic tradition is therefore anything that contributes to developing the knowledge that is required to participate in the process. It can be subjective or objective and may be intensely personal at one end of the spectrum (e.g. reflexivity) or distantly epiphenomenal (e.g. big data). Both 'known knowns' and 'known unknowns' drive the knowledge seeking process and concepts of proof and evidence relate to the perspective of the person examining the evidence (Denzin, 2011).

\section{Ethnographic techniques for social marketing}

In this section we highlight some of the more recent evolutions in ethnographic research to illustrate how researchers may engage and capture the dynamic and inter-relational aspects of consumers and their behaviours as enacted with other marketplace actors in the field of everyday life. We have selected visual ethnography, digital (virtual) ethnography, and rapid and short-term ethnography. It is beyond the scope of this paper to elaborate in detail the strengths, weaknesses and 'how to' approaches associated with each of these techniques. Nonetheless, we aim to inspire social marketers and marketers, more generally, to engage in reflexivity regarding taken-for-granted assumptions when conducting consumer research so that future efforts are more mindful of the consumer as an integrator and performer within a broader socio-cultural context.

\subsection{Visual ethnography}

One tool that allows the researcher to collect and display an understanding of the context is that of visual ethnography. Visual ethnography (VE) adds visual artefacts to the 
ethnographic record (e.g. photographs, videos, maps, clips) (Brace-Govan, 2007). Often these are complementary to auditory or documentary forms of data (Schwartz, 1989). However, increasingly such forms of data are useful in sharing completely the data where insights were gained (Pink, 2013). The use of VE as a research tool in social issues is not new (e.g.: Margolis, 1990; Rhodes and Fitzgerald, 2006), but as technologies change, then opportunities to collect, collate and present data to others have been expanded. No longer do ethnographers have to be accused of biased interpretations, the work is more concretely 'there' in a way that other forms of research are not (Schembri and Boyle, 2013). For example, you can provide a voice to refugee children along the Thai-Myanmar border (Oh, 2012), improve patient outcomes in intensive care units (Carroll et al., 2008) and enable global participation in heritage sites without degrading the environment (Servon and Pink, 2015). While VE offers promise as a research tool, VE requires fuller and more complex participant engagement with the data collection and collation exercise. This can impact on the amount of data collected. Missing data has the same implications as any empirical study; how far can you interpolate or extrapolate from your artefacts depends on the quality of the artefacts. In addition, due to the qualitative and interactive nature of data collection, researchers may influence the context and the participants simply by asking a question from a different perspective. The multifaceted nature of the role (e.g. spectator, interpreter, researcher, participant, artefact maker) will influence the outcome. Triangulation of data will be more challenging as capturing visual images is bounded by time; even with a digital camera, you cannot take the same picture twice.

\subsection{Digital (virtual) ethnography}


It is widely accepted that today's consumer makes little distinction between their online and offline "selves" in that people regularly share personal content and experiences via branded digital platforms (Facebook, Twitter, Pinterest) and virtual platforms such as blogs and vlogs. Digital platforms have thus evolved to be a new field for consumer inquiry and are rich sites to study participatory behaviours that reveal interesting accounts and lifestyle practices of the everyday consumer, or the unique representations of subcultural groups as lived out in contemporary society. Marketing scholar Robert Kozinets $(2002,2010)$ in defining his 'netnography' online marketing research technique argues being online for consumers is a 'real' existence for participants, which has "consequential effects on many aspects of behaviour, including consumer behaviour" (2002, p. 61). Netnography (and its variant digital/virtual ethnography) is a useful tool for social marketers as it focuses the researchers' attention on cultural insights by exploring people's online discourses and interactions as related to market-oriented issues and practices. Such explorations are not focused simply on the words and themes as gathered in online accounts, but involve deeper exploration of fluid and complex social interactions rich with underlying cultural meanings. This focus implies netnography is not 'just' about the people, but also focuses on documenting their behaviours and acts, as well as their social interactions within the digital environment, where you can be co-present while physically located any where in the world. For example, Hello Sunday Morning (HSM) is a blogging website that would be of interest to social marketers interested in the study of responsible drinking. The blogging website encourages participants to share their experiences following making a commitment to a period of sobriety, and to add their personal reflections on the role alcohol plays in their lives (Hamley and Carah, 2012). Researchers interested in exploring the social impact of alcohol have used HSM as an opportunity to explore consumer representations of alcohol identities (e.g. not being a 
drinking buddy) and to account for how young consumers' negotiate drinking rituals with peers and enjoyed experiences without drinking (Carah et al., 2015). Other social change researchers have embraced the study of social media for the purpose of engaging teens to think and talk about illicit drug use. This has been achieved through purposefully creating a dedicated platform (e.g. Sara Bellum Blog) to engage teens in online conversations about the science behind drug taking (Macario et al., 2013). Both these examples demonstrate the flexibility of social media sites as interactional research opportunities, which are open to engagement with target audiences of interest across time.

Social change digital platforms provide researchers with the ability to focus on behaviours in their natural environment; this is because researchers can have access (with permission) to the 'real' context where audiences discuss and share their lifestyle experiences. Furthermore, as users on social media engage in the creation of voluntary, spontaneous and authentic content, not forced by the market research inquiry, they provide relevant and rich data for netnographic study. On the one-hand, social marketers could construe social media users, or members of a particular site as a particular market segment that could be of interest in their own right. However, as indicated in the examples provided, netnography (or virtual ethnography) can be useful to social marketers as a flexible, unobtrusive method adapted to the purpose of studying consumer motivations, reflections and consumption behaviours, including their embedded social practices.

\subsection{Rapid and short term ethnography}

Rapid ethnography uses the same principles, tools and techniques as other forms of ethnography. However, it used when the context and the problem do not permit a longer 
time frame to examine. For example, when there is a rapidly changing environment and/or where researchers are not able to spare the time to become embedded in the community of practice. As such rapid ethnography is useful when there is a need to quickly create a socio-cultural profile of a group. While rapid ethnography has been framed as 'quick and dirty' (Millen, 2000), it has the potential to contribute to knowledge of context and human engagement in the environment in which behaviour is situated. The nature of rapid ethnography requires researchers to seek broad understanding with a more targeted focus of investigation in comparison with more traditional ethnographic approaches, yet this should not be confused with a narrow focus. Rapid methods demand researchers to consider multiple layers of socio-cultural context and of consumers inhibiting these spaces. Another version of this approach is short-term ethnography (Pink and Morgan, 2013), which is proposed as a technique that allows for deep knowledge of specific locales such as hospitals (Pink et al., 2014a), workplaces (Pink et al., 2014b) and homes (Pink et al., 2015) and families (Charlesworth and Baines, 2015). Pink proposes short-term ethnography as a practical solution to traditional wide-ranging and relatively intrusive ethnographic methods that can be difficult for field researcher and their participants. Time as such is not viewed as a limitation but rather as an essential element of the ethnographic process where ethnography 'takes on particular temporal and spatial characteristics, as well as specific qualities' (Pink and Morgan, 2013, p.359). Table 1 illustrates key characteristics of traditional versus rapid/short-term ethnographic approaches. 
Table 1: Characteristics of ethnographic approaches

\begin{tabular}{|l|l|l|l|}
\hline Factor & Anthropology & $\begin{array}{l}\text { "Traditional" } \\
\text { Ethnography }\end{array}$ & $\begin{array}{l}\text { Rapid/Short- } \\
\text { term } \\
\text { ethnography }\end{array}$ \\
\hline Level & Societal - macro & $\begin{array}{l}\text { Community - } \\
\text { macro/meso }\end{array}$ & $\begin{array}{l}\text { Social system - } \\
\text { meso/micro }\end{array}$ \\
\hline Focus & $\begin{array}{l}\text { Wide angle, all } \\
\text { inclusive lens }\end{array}$ & $\begin{array}{l}\text { Wide angle, } \\
\text { selective lens }\end{array}$ & $\begin{array}{l}\text { Narrow focus, } \\
\text { selective lens }\end{array}$ \\
\hline $\begin{array}{l}\text { Search } \\
\text { strategy }\end{array}$ & Culture & Norms & Exceptions \\
\hline Participants & $\begin{array}{l}\text { Researcher as } \\
\text { informant and } \\
\text { participant }\end{array}$ & $\begin{array}{l}\text { Many key } \\
\text { informants }\end{array}$ & $\begin{array}{l}\text { Fewer key } \\
\text { informants }\end{array}$ \\
\hline Knowledge & $\begin{array}{l}\text { Embodied } \\
\text { experiences }\end{array}$ & $\begin{array}{l}\text { Embodied } \\
\text { experiences }\end{array}$ & $\begin{array}{l}\text { Separate } \\
\text { experiences }\end{array}$ \\
\hline Data & $\begin{array}{l}\text { All data might be } \\
\text { valuable }\end{array}$ & $\begin{array}{l}\text { Useful' data is } \\
\text { collected and } \\
\text { examined }\end{array}$ & $\begin{array}{l}\text { Situationally } \\
\text { circumscribed } \\
\text { data }\end{array}$ \\
\hline Scope & Extensive & Comprehensive & Intensive \\
\hline Speed & Slow & Slower & Rapid \\
\hline $\begin{array}{l}\text { Level of } \\
\text { intrusion }\end{array}$ & High & High & Low \\
\hline
\end{tabular}

There is debate as to whether short-term ethnography is real or representative and whether or not its outcomes produce evidence that can be used by others in market situations (Wolff, 2004). However, as with all things research, tools and techniques evolve to suit the circumstances and conditions in which the researchers find themselves. Pink et al.'s work, in particular, has produced some impactful solutions to entrenched concerns such as safety and the environment.

\section{Conclusion}

This paper has examined some of the key underlying assumptions within social marketing that in effect limits its potential as a social change facilitator. Our intention is to ignite discussion, raise awareness and ultimately transition social marketers towards 
greater reflexivity in the development of social change programs. This is important because the prevailing individualised rationalities guiding objectives and methods of researchers, alongside policy-makers, produces consequences that subtract rather than enhance capability of consumers to engage social change (Askegaard et al., 2014).

Ethnographic tools allow social marketers to examine human behaviours within the behaviour ecology in which these behaviours occur. At the very least, they permit ecological validity to be established prior to the application of experimental methods seeking to predict behaviours. A social change agenda must extend beyond the individual and take into account the myriad of factors that influence the behaviour. People do not behave well in petri dishes. As such, ethnographic tools can enable non-laboratory observations of real world situations, performances and practices that may lead to greater levels of 'aha experiences' on behalf of the researchers. Insights developed using these methods are broader in scope, permit people to take risks in designing interventions and to say "if this then maybe that? or that? or perhaps that?", instead of designing interventions where the burden of proof limits the variables to only those things that may be controlled in a laboratory like setting. When it comes to fluid and complex social issues, some things may not stand still long enough for the researcher to codify them sufficiently to be measure them. In this case ethnographic traditions allow for a much greater array of alternative responses to the social issues faced by policy makers and social marketers alike.

Importantly, ethnography is a very humanistic research approach; conducted by humans, about humans and in human settings. Social marketing deals with designing 'interventions' in human behaviours that are damaging to health and wellbeing (in the fullest sense of that word). Reductionist thinking premised on the idea that individuals within their micro and meso settings can control the entire landscape of their lives limits the capacity to seek apposite solutions to human problems. Human insight to human 
problems requires an intimate knowledge of the human and the system in which the human is located. Ethnographic techniques are used to understand the complex internal dynamics of the ecosystem in which behaviours occur.

Ethnography permits greater opportunity for unknown unknowns to be uncovered. As Figure 1 illustrates, the ambiguity of process, the vagueness of goals and the many possible outcomes lead to undirected learning about the objects, artefacts and behaviours embedded in the system where the researcher is participating in different communities, spaces and with different people each time they undertake a research process. The fluidity and ambiguity is challenging for those trained in a biomedical scientific research tradition. However, along with Yuille et al. (2015), we argue that breakthrough new ideas come from innovation and ambiguity, and there are concomitant risks involved in these fuzzy processes. There is a risk that you will not know some 'thing' with any certainty at the end of your research process. You will, however, certainly know something that you did not know before. These discoveries may lead to more consumer-centric, socially relevant and aligned programs of change for social marketers.

Additionally, as with any research methods, there are no guarantees that research will lead to insight. However, ethnographic approaches produce much richer forms of data that can be viewed from many different perspectives, producing different outcomes each time. The reflexive cycle produces new understandings of the context, content and constituents each time it is engaged upon; thus there can be no single independent social reality, there are many possible realities, each providing opportunities to see things differently (i.e. insightful thinking). For social marketers, this enables research outcomes to be more generative of ideas than cross sectional surveys or experiments (for example). This is not to say that surveys are 'bad' things because they are not; it is more to suggest that surveys struggle to pick up the signs, symbols, indexicality or the interplay and nuances that exist 
within social settings when people are performing their daily lives. The lived experience has to be lived in order to be understood.

We recognise the list of ethnographic techniques presented in this paper is far from exhaustive. Our purpose in initiating discussion about research methodology in social marketing is to challenge the pervasive approach currently adopted by social marketers who readily apply discrete study findings to explain the cultural barriers and facilitators to social change. We hope that social marketers will be motivated to extend beyond takenfor-granted assumptions and consider more fully the consumer as a relational entity immersed within broader socio-cultural context that impacts behavioural outcomes. The trajectory of ethnographic thinking represents an opportunity for social marketers to explore more about the "why" of consumers' behaviours and uncover the dynamics of social interactions behind the 'micro-consumer' research project (i.e. individual level). Taking up an ethnographic approach will involve social marketers in not simply conducting a front-end research component positioned to inform the design and testing of campaign advertising and education materials, but in an ongoing inquiry that helps shape social and health solutions while simultaneously observing and interpreting the dynamics of human interactions. 


\section{References}

Agafonoff, N. (2006). Adapting ethnographic research methods to ad hoc commercial market research. Qualitative Market Research: An International Journal, 9 (2), 115-125.

Agar, M. H. (2001). Ethnography. In N. J. Smelser \& P. B. Baltes (Eds.), International Encyclopedia of the Social and Behavioural Sciences, (Vol. 12, pp. 4857 - 4862). Kidlington, Oxford UK, Elsevier Science.

Aggarwal, P., \& Basu, A. K. (2014). Value Co-Creation: Factors Affecting Discretionary Effort Exertion. Services Marketing Quarterly, 35 (4), 321-336.

Allard, F., \& Anderson, E. (2005). Ethnography Encyclopedia of Social Measurement (Vol. 1, pp. 833-843). New York, NY: Elsevier.

Allday, A. (2015). IBISWorld Industry Report M6941. Advertising Agencies in Australia. Australia: IBIS World reports ibisworld.com.au.

Andreasen, A. R. (2002). Marketing Social Marketing in the Social Change Marketplace. Journal of Public Policy \& Marketing, 21 (1), 3-13.

Askegaard, S., \& Linnet, J. T. (2011). Towards an epistemology of consumer culture theory

Phenomenology and the context of context. Marketing Theory, 11 (4), 381-404.

Askegaard, S., Ordabayeva, N., Chandon, P., Cheung, T., Chytkova, Z., Cornil, Y., Corus, C., Edell, J.A., Mathras, D., Junghans, A. F., Kristensen, D.B., Mikkonen, I., Miller, E.G., Sayarh, N. \& Werle, C. (2014). Moralities in food and health research. Journal of Marketing Management, 30 (17-18): 1800-1832.

Battle-Fisher, M. (2015). The Public, Private, and "Stepping on Toes" in Healthcare Application of Systems Thinking to Health Policy \& Public Health Ethics (pp. 23-27). New York: Springer.

Brace-Govan, J. (2007). Participant photography in visual ethnography. International Journal of Market Research, 49 (6), 735-750.

Brennan, L., Binney, W., Parker, L., Aleti, T., \& Nguyen, D. (2014). Social Marketing and Behaviour Change: Models, Theory and Applications. Cheltenham UK: Edward Elgar Publishing.

Brennan, L., Voros, J., \& Brady, E. (2011). Paradigms at play and implications for validity in social marketing research. Journal of Social Marketing, 1 (3), 100-119.

Bronfenbrenner, U. (1979). The ecology of human development: Experiments by nature and design. Cambridge, MA: Harvard University Press.

Bronfenbrenner, U. (2005). Making human beings human: Bioecological perspectives on human development. Thousand Oaks CA: Sage.

Bryman, A., \& Bell, E. (2007). Business research strategies. Oxford UK: Oxford University Press.

Capella, M. L., Taylor, C. R., \& Kees, J. (2012). Tobacco Harm Reduction Advertising in the Presence of a Government-Mandated Warning. Journal of Consumer Affairs, 46 (2), 235259.

Carah, N., Meurk, C. \& Hall, W. (2015). Profing Hello Sunday morning: who are the participants? International Journal of Drug Policy, 26, 214-216.

Carroll, K., Iedema, R., \& Kerridge, R. (2008). Reshaping ICU ward round practices using video-reflexive ethnography. Qualitative Health Rresearch, 18 (3), 380-390.

Chang, L., Jacobson, T. L., \& Zhang, W. (2013). A communicative action approach to evaluating citizen support for a government's smoking policies. Journal of Communication, 63 (6), 1153-1174.

Cherrier, H., \& Gurrieri, L. (2014). Framing social marketing as a system of interaction: A neo-institutional approach to alcohol abstinence. Journal of Marketing Management, 30 (7-8), 607-633. 
Charlesworth, S., \& Baines, D. (2015). Understanding the negotiation of paid and unpaid care work in community services in cross-national perspective: the contribution of a rapid ethnographic approach. Journal of Family Studies(ahead-of-print), 1-15.

Crawshaw, P. (2012). Governing at a distance: Social marketing and the (bio) politics of responsibility. Social Science \& Medicine, 75 (1), 200-207.

Dann, S., Harris, P., Sullivan Mort, G., Fry, M.L., \& Binney, W. (2007). Reigniting the fire: a contemporary research agenda for social, political and nonprofit marketing. Journal of Public Affairs, 7 (3), 291-304.

Denzin, N. K. (2011). The Politics of Evidence. In N. K. Denzin \& Y. S. Lincoln (Eds.), The SAGE Handbook of Qualitative Research Vol IV (pp. 645-657). Thousand Oaks California: SAGE

Dixon, H., Scully, M., Bridget, K., Chapman, K., \& Wakefield, M. (2014). Can counteradvertising reduce pre-adolescent children's susceptibility to front-of-package promotions on unhealthy foods?: Experimental research. Social Science \& Medicine, 116, 211-219.

Duong, H. T., Parker, L., Brennan, L., \& Florian, M. (2015). But I AM normal: safe? Driving in Vietnam, Journal of Social Marketing, 5 2), 105-124.

doi: http://dx.doi.org/10.1108/JSOCM-07-2013-0048

Fitchett, J. A., Patsiaouras, G., \& Davies, A. (2014). Myth and ideology in consumer culture theory. Marketing Theory, 14(4), 495-506.

French, J., Blair-Stevens, C., McVey, D., \& Merritt, R. (2010). Social marketing and public health: Theory and practice. Oxford UK: Oxford University Press.

Fry, M.L. (2007). Looking through the social marketing lens: Research issues and techniques. Australasian Journal of Market and Social Research, 15 (2), 35-43.

Fry, M.L. (2014). Rethinking social marketing: towards a sociality of consumption. Journal of Social Marketing, 4 (3), 210-222.

Gallegos, D., Russell-Bennett, R. \& Previte, J. (2011). An innovative approach to reducing risks associated with infant feeding: The use of technology, Journal of Nonprofit \& Public Sector Marketing, 23, 327-347.

Gallegos, D., Russell-Bennett, R., Previte, J., \& Parkinson, J. (2014). Can a text message a week improve breastfeeding? BMC Pregnancy \& Childbirth, 14, 374, http://www.biomedcentral.com/1471-2393/14/374.

Geller, E. S. (2002). The Challenge of Social Change: A Behavioral Scientist's Perspective. Social Marketing Quarterly, 8 (2), 15-24.

Grier, S., \& Bryant, C. A. (2005). Social marketing in public health. Annual Review of Public Health, 26, 319-329.

Guidry, J., Waters, R., \& Saxton, G. (2014). Moving social marketing beyond personal change to social change. Journal of Social Marketing, 4 (3), 240-260. doi: 10.1108/jsocm-02-2014-0014

Gurrieri, L., Previte, J., \& Brace-Govan, J. (2013). Women's bodies as sites of control: Inadvertent stigma and exclusion in social marketing. Journal of Macromarketing, 33 (2), 128-143.

Hackley, C., Bengry-Howell, A., Griffin, C., Szmigin, I., Mistral, W., \& Hackley, R. A. (2015). Transgressive drinking practices and the subversion of proscriptive alcohol policy messages. Journal of Business Research. In press - online at http://dx.doi.org/10.1016/j.jbusres.2015.03.011

Hamley, B., \& Carah, N (2012). One Sunday at a time: Evaluating hello Sunday morning. Online at http://www.fare.org.au/wp-content/uploads/2012/06/HSM-Evaluation-Final.pdf : FARE (Foundation for Alcohol Research \& Education). 
Humphreys, D., \& Manuel, E. (2014). Do flexible alcohol trading hours reduce violence? A theory-based natural experiment in alcohol policy. Social Science \& Medicine, 102, 1-9. http://dx.doi.org/10.1016/j.socscimed.2013.11.038

Hyman, M., Shabbir, H., Chari, S., \& Oikonomou, A. (2014). Anti-child-abuse ads: believability and willingness-to-act. Journal of Social Marketing, 4 (1), 58-76.

Kessels, L. T., Ruiter, R. A., Wouters, L., \& Jansma, B. M. (2014). Neuroscientific evidence for defensive avoidance of fear appeals. International Journal of Psychology, 49 (2), 8088.

Kim, H.-S., Sheffield, D., \& Almutairi, T. (2014). Effects of fear appeals on communicating potential health risks of unregulated dietary supplements to college students. American Journal of Health Education, 45 (5), 308-315.

Kozinets, R.V. (2002). The field behind the screen: Using netnography for marketing research in online communities. Journal of Marketing Research, 39, 61-72.

Kozinets, R.V. (2010). Netnography: Doing ethnographic research online. London: SAGE Publications Ltd.

Langford, R., \& Panter-Brick, C. (2013). A health equity critique of social marketing: where interventions have impact but insufficient reach. Social Science \& Medicine, 83, 133-141.

Layton, R. A. (2011). Towards a theory of marketing systems. European Journal of Marketing, 45 (1/2), 259-276.

Lefebvre, C. (2012). Transformative social marketing: co-creating the social marketing discipline and brand. Journal of Social Marketing, 2 (2), 118-129.

Macario, E., Krause, C. Katt, J.C., Caplan, S et al. (2013). NIDA engages teens through it blog: lessons learned. Journal of Social Marketing, 3 (1), 41-55.

Margolis, E., (1990). Visual Ethnogrpahy: Tools for Mapping the AIDS Epidemic. Journal of Contemporary Ethnography, 19 (3), 370-391.

Millen, D. R. (2000). Rapid ethnography: time deepening strategies for HCI field research. Paper presented at the Proceedings of the 3rd conference on Designing interactive systems: processes, practices, methods, and techniques.

Moss, A. C., Albery, I. P., Dyer, K. R., Frings, D., Humphreys, K., Inkelaar, T., Hardig, E., \& Speller, A. (2015). The effects of responsible drinking messages on attentional allocation and drinking behaviour. Addictive Behaviors, 44, 94-101.

doi: http://dx.doi.org/10.1016/j.addbeh.2014.11.035

NSMC (National Social Marketing Centre) (2015). Social Marketing Glossary. Retrieved 15 May 2015, 2015 from http://www.thensmc.com/sites/default/files/SM_glossary.pdf

Oh, S. A. (2012). Photofriend: creating visual ethnography with refugee children. Area, 44 (3), 382-288.

Panter, J., Corder, K., Griffin, S. J., Jones, A. P., \& van Sluijs, E. M. (2013). Individual, socio-cultural and environmental predictors of uptake and maintenance of active commuting in children: longitudinal results from the SPEEDY study. International Journal of Behavioral Nutrition and Physical Activity, 10 (1), 83. 1-12

Parkinson, J., Russell-Bennett, R., \& Previte, J. (2012). Mum or bub? Which influences breastfeeding loyalty. Australasian Marketing Journal, 20, 16-23.

Peattie, S., \& Peattie, K. (2003). Ready to fly solo? Reducing social marketing's dependence on commercial marketing theory. Marketing Theory, 3 (3), 365-385.

Peattie, S., Peattie, K., \& Thomas, R. (2012). Social Marketing as Transformational Marketing in Public Services: The Case of Project Bernie. Public Management Review, 14 (7), 987-1010.

Pink, S. (2012). Situating everyday life: Practices and places. London UK: Sage Publications.

Pink, S. (2013). Doing visual ethnography. London UK: Sage Publications. 
Pink, S., \& Morgan, J. (2013). Short-Term Ethnography: Intense Routes to Knowing. Symbolic Interaction, 36 (3), 351-361.

Pink, S., Morgan, J., \& Dainty, A. (2014a). The safe hand: Gels, water, gloves and the materiality of tactile knowing. Journal of Material Culture, 19 (4), 425-442. doi: doi: $10.1177 / 1359183514555053$

Pink, S., Morgan, J., \& Dainty, A. (2014b). Safety in movement: Mobile workers, mobile media. Mobile Media \& Communication, 2 (3), 335-351.

Pink, S., Morgan, J., \& Dainty, A. (2015). Other people's homes as sites of uncertainty: ways of knowing and being safe. Environment and Planning A, 47 (2), 450-464.

Polonsky, M. J., Renzaho, A. M. N., \& Brijnath, B. (2010). Integrating socio-cultural paradigms in nonprofit marketing - the case of blood donation among African communities in Australia. International Review on Public and Nonprofit Marketing, 7 (2), 101-112.

Pykett, J., Jones, R., Welsh, M., \& Whitehead, M. (2014). The art of choosing and the politics of social marketing. Policy Studies, 35 (2), 97-114.

Rhodes, T., \& Fitzgerald, J. (2006). Visual data in addictions research: Seeing comes before words? Addiction Research \& Theory, 14 (4), 349-363.

Schembri, S., \& Boyle, M. V. (2013). Visual ethnography: Achieving rigorous and authentic interpretations. Journal of Business Research, 66 (9), 1251-1254.

Schwartz, D. (1989). Visual ethnography: Using photography in qualitative research. Qualitative Sociology, 12 (2), 119-154.

Servon, L. J., \& Pink, S. (2015). Cittaslow: Going Glocal in Spain. Journal of Urban Affairs. Ahead-of-print online at: DOI: 10.1111/juaf.12169

Smith, R. E., \& Yang, X. (2004). Toward a general theory of creativity in advertising: Examining the role of divergence. Marketing Theory, 4 (1-2), 31-58.

Sniehotta, F., Presseau, J., \& Araujo-Soares, V. (2014). Time to retire the theory of planned behaviour. Health Psychology Review, 8 (1), 1-7. doi: 10.1080/17437199.2013.869710

Snitow, S., \& Brennan, L. (2011). Reducing drunk driving-caused road deaths: Integrating communication and social policy enforcement in Australia. In H. Cheng, P. Kotler \& N. Lee (Eds.), Social Marketing for Public Health: Global Trends and Success Stories (pp. 383-403). Sudbury, MA: Jones and Bartlett Publishers.

Stone, M. (2004). Consumer insight: How to use data and market research to get closer. Kogan Page Publishers.

Sweeney, A. M., \& Moyer, A. (2015). Self-affirmation and responses to health messages: a meta-analysis on intentions and behavior. Health Psychology, 34 (2), 149-159. doi: $10.1037 /$ hea0000110

Szmigin, I., Bengry-Howell, A., Griffin, C., Hackley, C., \& Mistral, W. (2011). Social marketing, individual responsibility and the "culture of intoxication". European Journal of Marketing, 45(5), 759-779. doi: 10.1108/03090561111120028

Tadajewski, M., Chelekis, J., DeBery-Spence, B., Figueiredo, B., Kravets, O., Nuttavuthisit, K., Penaloza, L and Moisander, J. (2014). The discourse of marketing and development: Towards 'critical transformative marketing research, Journal of Marketing Management, 30 (17-18), 1728-1771.

Tapp, A., Pressley, A., Baugh, M., \& White, P. (2013). Wheels, Skills and Thrills: A social marketing trial to reduce aggressive driving from young men in deprived areas. Accident Analysis \& Prevention, 58, 148-157

The VOICE Group (2010). Motherhood, marketization, and consumer vulnerability. Journal of Macromarketing, 30 (4), 384-397. 
Warin, M., Zivkovic, T., Moore, V., Ward, P., \& Jones, M. (2015). Short horizons and obesity futures: Disjunctures between public health interventions and everyday temporalities. Social Science \& Medicine. 128, 309-315

Wolff, S. (2004). 5.1 Ways into the FieId and their Variants. In U. Flick, E. von Kardorff \& I. Steinke (Eds.), A Companion to Qualitative Research (pp. 195-202). London, UK: SAGE Publications Inc.

Woolf, S. H., Purnell, J. Q., Simon, S. M., Zimmerman, E. B., Camberos, G. J., Haley, A., \& Fields, R. P. (2015). Translating Evidence into Population Health Improvement: Strategies and Barriers. Annual Review of Public Health, 36, 463-482

Yuille, J., Varadarajan, S., Vaughan, L., \& Brennan, L. (2015). Leading Through Design: Developing Skills for Affinity and Ambiguity. Design Management Journal, 9 (1), 113-123. 